\title{
MULHER, DIREITO E SAÚDE: repensando o nexo coesivo*
}

\section{Rosa Maria Godoy Serpa da Fonseca**}

RESUMO:Esse artigo é construido a partir de três elementos básicos: mulher, direito e saúde, articulados entre si a partir de: 1) considerações acerca das condições objetivas de constituição das mulheres enquanto sujeitos sociais na sociedade contemporânea; 2) direitos das mulheres como direitos humanos e 3) direito das mulheres à saúde no contexto da implementação do PAISM (Programa de Atenção Integral à Saúde da Mulher), como focalização do SUS (Sistema Único de Saúde).

KEY WORDS: gênero e saúde, direitos das mulheres, direito à saúde, PAISM/SUS

*Conferência proferida na Conferência Municipal sobre Saúde da Mulher "Mulher, direito e saúde" preparatório para a IV Conferência Municipal de Saúde de Goiânia, 13/03/98

${ }^{\star \star}$ Enfermeira. Professora Associada do Departamento de Enfermagem em Saúde Coletiva da Escola de Enfermagem da Universidade de São Paulo. Conselheira do Conselho Estadual da Condição Feminina de São Paulo. Vice-coordenadora do NEMGE (Núcleo de Estudos da Mulher e Relações Sociais de Gênero da Universidade de São Paulo). 
Para compreender o que significa ser mulher e as especificidades da vida das mulheres, há que se compreender como mulheres e homens se constituem como sujeitos sociais, no contexto da sociedade contemporânea. Extensamente exploradas nos estudos feministas, as relações sociais estabelecidas entre mulheres e homens, relações de poder, parecem ter sua gênese na constituição das sociedades, tanto quanto na divisão sexual do trabalho. Isso explicaria, entre outras coisas, a naturalização do trabalho doméstico e do cuidado com as crianças (além de gerá-las) como pertencentes ao mundo feminino, bem como, de outro lado a inserção social dos homens no espaço público.

A base de tal pensamento situa-se na visão idealista de familia como espaço de ausência de conflitos, tanto quanto na separação das esferas do público e do privado, estabelecendo para homens e mulheres lugares distintos. Foi no contexto das lutas feministas, principalmente as mais recentes, que emergiram as possibilidades de reflexão sobre a dicotomização entre os mundos público e privado e a necessidade de compreender a sua integração e articulação. Sob a bandeira de que "o pessoal é político", as feministas têm envidado inúmeros esforços na derrubada do mito da divisão entre o público e o privado e, com isso, tornado suas questões passiveis de serem compreendidas como histórica e socialmente construídas. Se, por um lado, o capitalismo consolidou o trabalho da mulher entre quatro paredes, naturalizando funções como mãe e dona de casa, por outro, tem sido esse o modo de produção no contexto do qual, na história, mais se tem lidado com as questões das mulheres, procurando-se sua gênese e possibilidades de superação.

“Já vão longe nossas ilusões a respeito do racionalismo e da objetividade e, junto com elas, foram-se também nossos tão acalentados sonhos de uma família que fosse o refúgio contra a luta e a competição. Em nosso realismo recentemente conquistado, o pessoal é político e, principalmente, a família é política. Fundada na hierarquia e na dominação, que ela tem reproduzido através da história, a familia - esse mais intimo espaço das relações pessoais - requer uma resposta politica nessa era tão eminentemente politizada em que vivemos." (FOX-GENOVESE, 1992)

Segundo MATOS (1994), "o processo de construção e de segmentação do público/ privado carrega na sua trajetória inter-relações desenvolvidas através de um discurso legitimador que vem atrelado, desde a origem, a um ocultamento de toda uma tensão entre os sexos..." Tal discurso, que legitima a falsa universalidade entre os limites do público e do privado foram definidos e tornaram-se mais precisos na Inglaterra vitoriana do século XIX 
que representa o lar e a família, em termos naturais e a esfera pública como instância histórica. "Foi no contexto da herança vitoriana que se construiu o dualismo público/privado, reafirmando o privado como espaço da mulher e representando-a como vítima de sua própria natureza, ao destacar a maternidade como necessidade e o espaço privado como locus de realização das potencialidades femininas" (MATOS, 1994)

Num trabalho clássico de análise da maternidade, Badinter desmistifica a maternidade atribuindo-Ihe a historicidade que the é inerente. Segundo a autora, o amor materno também é construído socialmente como forma de controle e submissão (pacifica) das mulheres às necessidades sociais do trabalho doméstico. É no contexto dos três discursos em defesa da criança formulados para atribuir-lhe valor (imprescindivel para que se constituísse como força de trabalho) apontados pela autora que podemos encontrar os fundamentos do trabalho da mulher voltado predominantemente para a reprodução no contexto do mundo privado: 1) o discurso econômico enfatizou a importância da população e particularmente da criança como riqueza econômica potencial. Nascido no século XVIII, com o nascimento da noção de Estado, ressurgiu no século XIX e consolidou-se no $X X$ inclusive matizando as políticas públicas de proteção à infância e à maternidade, vigentes até hoje. 2) discurso filosófico, principalmente da Filosofia das Luzes propagou o desenvolvimento do amor e da sua expressão através das idéias de igualdade e de felicidade e 3) o discurso dirigido às mulheres que, sensibilizadas através das idéias de saúde e beleza, harmonia e felicidade, foram sendo construidas como os grandes depositórios da humanidade no que diz respeito à construção dos lares/ filhos/ famílias felizes e saudáveis, loci privilegiados de construção dos sujeitos moldados às exigências do sistema social. (BADINTER, 1994)

A consolidação da família na modernidade ocorreu primeiro na burguesia e depois, através da disseminação das suas idéias e valores, nas demais classes sociais. De igual maneira foi construída a função social das mulheres e o que se esperava delas: (boas) mães, passaram a dedicar-se inteiramente aos filhos; (fiéis e dedicadas) esposas, responsabilizaram-se pelo cuidado e manutenção da força de trabalho dos maridos e, esquecidas de si mesmas, incorporaram tais funções como naturais e exclusivas, mesmo quando a necessidade de subsistência as resgatou parcialmente dos lares para as fábricas e demais espaços de produção social. Nesse momento construíram-se (boas) trabalhadoras/ profissionais sem abrir mão das funções anteriores, objetivando sempre compatibilizá-las, como se só a elas coubesse a superação das dificuldades e contradições inerentes ao desempenho dessa multiplicidade de papéis. (BADINTER, 1994) 
Em um trabalho sobre a produção e reprodução social, Combes e Haicault ressaltam a subordinação da reprodução à produção como determinante básico para a subordinação das mulheres aos homens, a partir da divisão sexual do trabalho. Através de uma recuperação histórica, enfatizam a não peculiaridade do modo de produção capitalista na designação prioritária dos homens para a produção e das mulheres para a reprodução. No entanto, foi nesse sistema que isso se consolidou. A análise minuciosa desse processo e das relações de força ocorridas no âmbito da familia e do espaço público, as leva a concluir que "a relação social antagônica entre os sexos exprime-se, indiferentemente, na produção e na reprodução. Ela não está, de modo algum, circunscrita à familia; assim como, aliás, a relação social entre o capital e o trabalho não está circunscrita à produção." Fazem parte da constituição da sociedade e do seu suporte ideológico que ligam a família ao Estado. " $A$ familia, tal como a conhecemos e, mais amplamente, o conjunto dos aparelhos atuais da reprodução são também o resultado de uma delegação crescente de poder dos capitalistas ao Estado, em tal questão. O resultado de uma intervenção tentacular e multiforme do Estado, assenhorando-se das esferas da habitação, da educação, da saúde e da previdência, etc, mantendo e desenvolvendo um aparelho policial e judicial, normas legislativas, em sintese, tudo o que contribua para fixar as condições sociais de reprodução. A família é também, e de forma indissociável, o resultado de um Estado - e, de forma mais geral, de um poder político onipresente - que produz os suportes ideológicos, morais e simbólicos, reforçando a exploração e super-exploração das mulheres, indiscriminadamente; permitindo ou facilitando a interiorização das normas sociais de sexo e de classe, particularmente através de um discurso que, paradoxalmente valoriza a esfera privada e o individualismo!" (COMBES; HAICAULT, 1986)

Mesmo quase uma década depois de escrito esse trabalho, quando denota-se um movimento de enxugamento das funções do Estado neoliberal, suas considerações persistem quase totalmente verdadeiras, na medida em que agora, não sendo mais (tanto) da competência do Estado a manutenção das condições da reprodução (em função da delegação de muito disso ao setor privado), na verdade, a família continua sendo constituída por influência dele e de seu sistema de idéias e representações, na medida em que devolve a ela (e à sua relação com o setor privado) a responsabilidade pela manutenção da força de trabalho. É à família que agora cabe prover tais condições já que o Estado sucateado (propositadamente) não tem mais possibilidades para isso. $E$ isso deve ser feito dentro do mesmo sistema de idéias que antes aceitava a tutela do Estado, passando agora a ter que aceitar a renúncia a essa tutela em nome dos déficits públicos, das condições cada vez mais difíceis de constituição e manutenção dos serviços públicos. 
Uma pesquisa sobre a assistência à saúde da criança em idade escolar constata que a família e, dentro dela, única e exclusivamente a mãe, é responsabilizada tanto pelos agravos ao processo saúde-doença das crianças como pela busca de solução para os mesmos. Isso, por parte dos três segmentos implicados na assistência a esse grupo populacional, quais sejam: os componentes da equipe de saúde, as professoras e as próprias mães que, na sua trajetória de vida, em contato com os anteriores, introjeta o discurso ideologizado e o reproduz, considerando-se ao mesmo tempo culpada pelos erros em relação aos filhos e a única responsável pela sua solução. (OLIVI, 1996)

É também o espaço familiar que permite a compreensão da articulação existente entre o trabalho doméstico e extra-doméstico para as mulheres. Um estudo sobre o trabalho noturno de pessoal de enfermagem e saúde revelou a perversidade da relação entre ambos como carga para as mulheres. Essa perversidade foi tamanha que justificou a autora a referir-se às mulheres estudadas como "verdadeiramente um grupo de sobreviventes". A esse respeito, cita: "Ao analisar-se o trabalho das profissionais de enfermagem, fica evidente a impossibilidade de dissociação do trabalho profissional, realizado no hospital, do trabalho doméstico, no universo familiar. À pesada carga de trabalho profissional, as trabalhadoras, (...) ainda acrescentavam à sua jornada semanal, em média, 22,7 horas de trabalho doméstico, implicando, para a maioria, um esforço físico considerado moderado ou pesado."(MENEZES, 1996)

Se, no espaço da familia, as relações entre homens e mulheres são conflitivas, o espaço extra-familiar não deixa por menos. No mundo do trabalho, da política, das demais relações sociais, as mulheres nitidamente são portadoras de uma situação de subalternidade impar, como veremos também nesse trabalho.

\section{MULHER E POLITICAS PÚBLICAS}

Para Caroline Moser, especialista em planejamento e gênero, as necessidades das mulheres surgem em virtude dos três tipos de papéis relativos aos diferentes trabalhos que elas desempenham na sociedade:

1. Trabalho reprodutivo: compreende a responsabilidade de criação e educação dos filhos e as tarefas domésticas empreendidas pela mulher requeridas para garantir a manutenção e a reprodução da força de trabalho. Não só inclui a reprodução biológica 
como também o cuidado e a manutenção da força de trabalho (crianças e jovens em idade escolar). Historicamente na maior parte da sociedade são as mulheres que cuidam das crianças e isso se relaciona naturalmente com a reprodução de toda a vida humana. Assim, as mulheres se responsabilizam não só pelo cuidado dos filhos como de outras pessoas da família como velhos, doentes, etc. Se bem que o termo reprodução biológica refira-se rigidamente à reprodução da espécie, o termo reprodução do trabalho vai mais além. Inclui o cuidado, a socialização e a manutenção de indivíduos no decorrer da vida, para assegurar a continuação da sociedade através da geração seguinte. É importante distinguir esse termo de "reprodução social" que é definido como os processos muito mais amplos mediante os quais se recriam e perpetuam as principais relações de produção na sociedade. Estas não só incluem a produção e a manutenção da força de trabalho assalariada como a reprodução do capital (MOSER, 1995).

Na interioridade as características do trabalho doméstico são:

- ao mesmo tempo que é indispensável, é invisível, tornando-se visível somente na ausência;

- é tido como de responsabilidade e atribuição exclusiva de mulheres, geralmente da mãe/ esposa e, na falta dessas, de outra pessoa que lhe substitua, sendo executado por elas ou sob seu comando. A participação dos homens ou de outras pessoas da familia, quando ocorre, é limitada à ajuda à responsável, nunca à assunção de parte dele que, em geral, é pontual, intermitente e envolve a realização de tarefas específicas;

- é distribuido durante todo o dia, sendo impossivel às suas exercentes fixarem uma jornada de trabalho doméstico. Geralmente o tempo dispendido é o tempo livre da mulher, no caso das que também trabalham fora de casa ou dependente dos horários fixos dos outros componentes da familia, no caso das mulheres que não trabalham fora. No trabalho de MENEZES (1996), as mulheres o executavam preferentemente na ausência dos maridos e dos filhos ou nos finais de semana.

- toma tempo das mulheres no que se refere ao cuidado de si mesmas. A mulhermãe, dona de casa, em geral, é a última pessoa com quem ela mesma se preocupa, não sendo incomum referirem, por exemplo, falta de tempo para o controle da situação de saúde, em função do acúmulo das tarefas do lar, quando não deste e do trabalho realizado fora dele. 
- é monótono, repetitivo, com poucas possibilidades de ser criativo, dada a submissão às rotinas que, em geral, são estabelecidas pelas próprias mulheres, para dar conta de todas as suas atribuições. (FONSECA, 1996a)

2. Trabalho produtivo: compreende o trabalho realizado por mulheres e homens por um pagamento em dinheiro ou espécie. Inclui tanto a produção para o mercado com um valor de câmbio e a produção de subsistência doméstica com um valor de uso real, como também a produção com um valor de câmbio potencial. Para a mulher inserida na produção agrícola, isso inclui trabalho como agricultora independente, esposa de campesino e trabalhadora assalariada. As condições de trabalho das mulheres são extremamente desfavoráveis em relação ao trabalho dos homens indo desde a distribuição das ocupações como os ganhos que chegam no máximo a $64 \%$ do valor do mesmo trabalho quando executado por homens. (MOSER, 1995)

No espaço desse trabalho também as mulheres encontram-se em situação de subalternidade em relação aos homens. Assim, ocupam funções de menor prestígio social, recebem cerca de $54 \%$ do salário dos homens pela mesma função, inserem-se em ocupações que referem-se ao fazer histórico das mulheres de cuidado dos demais, em tempos de crise aceitam trabalhos tidos como pouco valorizados, diferentemente dos homens que selecionam as áreas em que se inserem no setor produtivo, etc. Todas essas questões remetem para uma diferenciação de gênero no que se refere ao trabalho de homens e mulheres. (FONSECA, 1996a)

3. Gestão e política comunitária: compreende as atividades empreendidas pelas mulheres sobretudo no âmbito da coletividade como uma extensão do seu trabalho reprodutivo, isto é, para assegurar a provisão e manutenção dos recursos de consumo coletivo como a água, a saúde, a educação. É um trabalho voluntário, não remunerado, empreendido durante o tempo livre. Ao contrário, a função político-comunitária compreende as atividades levadas a cabo pelos homens no âmbito da coletividade que se organizam no nivel político formal. Esse trabalho é remunerado, seja direta ou indiretamente mediante salários ou incrementos de status e poder. É importante assinalar que os homens também trabalham na coletividade. Entretanto, as divisões de trabalho por gênero são tão importantes nesse âmbito como no da casa e da família. A divisão espacial entre o mundo público do homem e o mundo privado da mulher significa que para a mulher a vizinhança é uma extensão do terreno doméstico enquanto que para o homem é o mundo público da política. Isso significa que enquanto a mulher em suas funções de esposa e mãe, adscritas por gênero, está inserida na gestão, os homens estão inseridos na política da coletividade. (MOSER, 1995) 
A compreensão dos tipos de trabalhos desempenhados pelas mulheres vem subsidiar a compreensão da formulação das políticas de gênero, diretamente relacionadas com as necessidades das mulheres que quando vistos sob o prisma das desigualdades convertemse em necessidades de gênero.

Para MOLYNEUX (1984) necessidade distingue-se de interesse, definindo esse como preocupação priorizada que se traduz em necessidade. Assim, os interesses de gênero são aqueles que as mulheres (ou os homens) podem desenvolver em virtude de sua posição social através de seus atributos de gênero. Podem ser tanto estratégicos como práticos derivando-se cada um de uma maneira diferente e compreendendo distintas implicações para a subjetividade das mulheres (ou dos homens).

Para essa autora, as necessidades estratégicas de gênero são aquelas que as mulheres identificam em virtude de sua posição subordinada aos homens na sociedade. Variam de acordo com contextos particulares e se relacionam com as divisões do trabalho, de poder e de controle por gênero e podem incluir assuntos como os direitos legais, a violência doméstica, a igualdade de salários e o controle das mulheres sobre o seu próprio corpo. Satisfazer as necessidades estratégicas ajuda as mulheres a conseguir uma maior igualdade. Também modifica os papéis existentes e por isso desafia a posição subordinada da mulher. As necessidades estratégicas de gênero podem incluir todo ou parte do que segue: "a abolição da divisão sexual do trabalho; o alívio da carga de trabalho doméstico e do cuidado com as crianças; a eliminação das formas institucionalizadas de discriminação tais como o direito à propriedade da terra ou o acesso ao crédito; o estabelecimento de igualdade política; liberdade de eleição sobre a maternidade e a adoção de medidas adequadas contra a violência e contra o controle masculino sobre a mulher" (MOLYNEUX, 1984).

As necessidades práticas de gênero são as necessidades que as mulheres identificam em virtude de seus papéis socialmente aceitos pela sociedade. Elas não desafiam as divisões do trabalho por gênero ou a posição subordinada das mulheres na sociedade, ainda que surjam delas. Essas necessidades são uma resposta à necessidade percebida imediata, identificada dentro de um contexto específico. Surgem a partir das condições concretas em que vivem as mulheres. Derivam de sua posição na divisão sexual do trabalho por gênero e de seus interesses práticos pela sobrevivência humana. São de natureza prática e, em geral, estão relacionadas com a inadequação das condições de vida como o abastecimento de água, a atenção de saúde, o emprego, etc. (MOLYNEUX, 1984) 
Segundo a compreensão e priorização desse ou daquele tipo de necessidade, na América Latina vários têm sido os enfoques da articulação entre Mulher e Desenvolvimento na formulação das políticas públicas. Entre eles, segundo MOSER (1995) destacam-se os seguintes, mostrados em detalhes no Quadro I, em anexo:

1. Enfoque de Bem- Estar

2. Enfoque de eqüidade

3. Enfoque anti-pobreza

4. Enfoque de eficiência

5. Enfoque de fortalecimento

De todos eles, o mais recente, o de empoderamento, é o que mais corresponde aos anseios dos atuais movimentos emancipatórios das mulheres. Trata-se do último enfoque das políticas feministas na América Latina e surgiu no bojo do movimento pela revisão dos paradigmas para a compreensão das condições de vida da população do Terceiro Mundo. Reconhece as desigualdades entre homens e mulheres e concebe as origens da subordinação das mulheres predominantemente na familia, porém também enfatiza o fato de que a mulher vive em condições diferentes de opressão segundo sua raça, classe, história colonial e atual posição na ordem econômica internacional. Por isso, esse enfoque sustenta que as mulheres têm que desafiar as estruturas e as situações opressivas simultaneamente nos diferentes niveis. Ainda que reconheça a importância de que as mulheres incrementem seu poder, sem dúvida identifica esse poder menos em termos de dominação sobre outros (como o suposto de que os ganhos das mulheres implicam em perdas para os homens) e mais em termos de sua capacidade para incrementar sua auto-confiança e sua fortaleza interna. Isso é identificado como o direito a determinar as opções na vida e influir na direção das mudanças mediante a capacidade para obter o controle sobre recursos materiais e não materiais fundamentais. Põe menos ênfase em elevar o status da mulher em relação aos homens e busca empoderá-las mediante a redistribuição do poder dentro e entre as sociedades. (MOSER, 1995)

A mais conhecida articulação do enfoque de empoderamento tem sido feita pelo Projeto DAWN (Alternativas de Desenvolvimento com Mulheres por uma Nova Era) que surgiu de uma confluência de mulheres e grupos de mulheres estabelecida antes da Conferência Mundial de Mulheres em Nairobi (1985), com o propósito de analisar a situação das mulheres no mundo e formular uma visão de sociedade alternativa que elas definiram como segue:

"Queremos um mundo onde não existam desigualdades baseadas na classe, em gênero, em raça, em nenhum país, nem nas relações entre os 
países. Queremos um mundo onde as necessidades básicas se convertam em direitos básicos e onde a pobreza e todas as formas de violência sejam eliminadas. Queremos que cada pessoa tenha a oportunidade de desenvolver plenamente seu potencial e criatividade e onde os valores femininos de cuidados para com os outros e solidariedade caracterizem as relações humanas. Em um mundo assim o papel reprodutivo das mulheres será redefinido: o cuidado das crianças e da familia será de responsabilidade das mulheres, dos homens e da sociedade em geral. Somente aprofundando os vínculos entre a igualdade, o desenvolvimento e a paz poderemos mostrar a intrincada relação que existe entre os "direitos básicos" de todos e as transformações das instituições que subordinam as mulheres. Ambos podem ser alcançados através do autoempoderamento das mulheres." (DAWN, 1985)

"Para que as mulheres encontrem justiça na sociedade a nova era imaginada pelo DAWN requer a transformação das estruturas de subordinação que têm sido tão adversas às mulheres. São essenciais as mudanças nas leis, códigos civis, sistemas de direito à propriedade, controle sobre o corpo das mulheres, códigos trabalhistas e nas instituições sociais e legais que subscrevem o controle e o privilégio masculinos." (MOSER, 1995)

A noção de fortalecimento pode ser ancorada no conceito de "empowerment", termo utilizado na Saúde Pública a partir do seu oposto powerlessness na medida em que o foco principal da ação recai sobre o processo de mudança da auto percepção do indivíduo. A definição proposta por WALLERSTEIN (1994) remete a uma dimensão na qual os indivíduos ampliam o controle sobre suas vidas no contexto da participação em grupos visando as transformações na realidade social e politica em que vivem. "The goals of an empowerment social action process, therefore, are individual and community capacity building, control over life decisions, equity of resources and improved quality of life" ( WALLERSTEIN, 1994)

Tais processos distinguem-se da abordagem tradicional de mudança de comportamento pois destacam a necessidade de se ampliar o âmbito da ação para que

10 Projeto DAWN (Alternativas de Desenvolvimento com Mulheres por uma Nova Era) nasceu em Bangalore (Índia). Em 1985 entre as instituições colaboradoras estavam: AAWORD (Associação Africana de Mulheres para a Investigação e Desenvolvimento); WAND (Unidade de Mulheres e Desenvolvimento da Universidade das Índias Ocidentais); APCD (Centro de Desenvolvimento da Ásia e do Pacífico); Instituto Cristiano Michelson (CMI) da Noruega, com apoio da Fundação Ford, Conselho de População e Organismo Norueguês para o Desenvolvimento Internacional (NORAD). 
contemplem as dimensões singular (relativa à subjetividade, expressa como auto-estima, motivação), particular (relativa ao grupo social no qual se insere a pessoa) e estrutural (relativa à estrutura política, jurídica e ideológica).

A utilização desse conceito para o trabalho em saúde baseia-se na visão de que os perfis epidemiológicos se diferenciam de acordo com as condições de vida, assumindo importância também a falta de controle dos indivíduos sobre as suas vidas. A promoção e a educação à saúde se configuram como instrumentos para capacitar os individuos a aumentar o controle sobre os determinantes da saúde. Referem-se portanto, às transformações nas relações de poder que se estabelecem na sociedade. No caso da ação junto aos trabalhadores implica reconhecer que as condições de trabalho se diferenciam de acordo com o grau de controle que os trabalhadores têm do processo de trabalho. Assim, a intervenção visa aumentar o espaço para o exercício do poder tanto individual como coletivo, entendendo-se individual e coletivo não como polos opostos mas na relação dinâmica que se estabelece entre eles.

Para as mulheres, empoderamento significa o auto-reconhecimento da sua situação de subalternidade social e a busca de meios e estratégias para vencê-la, garantindo-lhes autonomia e liberdade de ação tanto no mundo público como no privado. Através do empoderamento seriam satisfeitas as necessidades estratégicas de gênero que, como vimos anteriormente, são aquelas que visam a transformação das condições de subalternização das mulheres aos homens na sociedade

\section{OS DIREITOS DAS MULHERES SÃO DIREITOS HUMANOS}

Historicamente, a partir da constituição da noção de Estado, as políticas sociais surgem do embate entre os interesses das classes e grupos sociais dominantes e dominados, como resposta à adoção da idéia de direitos. A primeira experiência humana em relação a isso deu-se no contexto da Revolução Francesa subjacente à noção de cidadania.

No ano de 1998 comemora-se o Jubileu de Ouro (50 anos) da Declaração Universal dos Direitos Humanos. Adotada pela Assembléia Nacional Francesa em 26 de agosto de 1789, fiel ao ideário da Revolução Francesa (1789) e sob influência da Declaração da Independência dos Estados Unidos votada pelo Congresso Americano em 4/7/1776, chamouse "Declaração dos Direitos do Homem e do Cidadão", transpirando masculinidade por todos 
os poros. Sim, porque se hoje a observância dos direitos humanos significa o acesso universal às condições mínimas de cidadania, independentemente de raça, religião, sexo, idade etc, nem sempre foi assim. Na sua gênese, o conceito de cidadania era individualista e visava proteger a liberdade, a segurança e a integridade física e moral da pessoa, e garantir-lhe o direito de participação na vida pública. Dado que o espaço público era masculino por excelência, a Declaração automaticamente excluía as mulheres, considerando-as não cidadãs, tanto quanto os não brancos, os pobres, os não letrados, as crianças etc.

Com relação às mulheres, cabe citar o Vindication of the rights of Woman de Mary Wollstonecraft na Inglaterra, em 1790, como primeira iniciativa de extensão dos direitos de cidadania às mulheres. Autora de uma produção intensa voltada para as questões dos direitos politicos, educação feminina e independência econômica das mulheres, Mary Wollstonecraft utilizou como ponto de partida para suas obras as duas declarações anteriores junto com o conceito de direitos individuais, inalienáveis e universais, ainda desconhecido na Inglaterra de seu tempo. Essa autora viria influenciar mais tarde no Brasil, praticamente todo o pensamento de Nisia Floresta Brasileira Augusta, precursora do feminismo nacional. (DUARTE, 1989)

Na França, Condorcet já havia aberto o debate a respeito das causas das mulheres e publicado também em 1790 seu Essai sur l'admission des femmes au droit de cité, disputando com Mary Wollstonecraft a iniciação do movimento pelos direitos das mulheres. "Ainda que possa parecer estranho ... o pensamento de Condorcet, para sua época, era crítico e, até certo ponto, revolucionário. Dirigia-se contra as classes poderosas dominantes na época: a Igreja, o poder feudal e o Estado oligárquico, que se atribuiam o controle de todo o conhecimento científico. Condorcet indicava a necessidade de romper com esse monopólio do saber, livrando as ciências da sociedade dos interesses e paixões das classes feudais, das doutrinas teológicas, dos argumentos de autoridade da Igreja e de todos os 'dogmas fossilizados' “ (MINAYO, 1992). Com base nisso, é de se compreender como e porque o precursor do positivismo colocava-se ao lado das mulheres.

O inconformismo levou também a feminista francesa Olympe de Gouges a lançar, em 1791, Les droits de la femme et de la citoyenne (Declaração dos Direitos da Mulher e da Cidadã). Tão revolucionária quanto Robespierre, Danton, Marat e outros, acreditava que poderia ter acolhida por eles sua pretensão de garantir às mulheres igualdade de direitos em relação aos homens. Por isso acabou sem cabeça, considerada inimiga da revolução, assassinada pelos próprios companheiros sob a acusação de "ter querido ser homem de Estado e ter esquecido as virtudes próprias de seu sexo" (DUARTE, 1989; CONSELHO, 1998) 
No Preâmbulo de Les droits de la femme et de la citoyenne (1793) reivindica o direito das mulheres (chamadas por ela de mães, filhas e irmãs) de pertencerem à Assembléia Nacional, ou seja, de serem visíveis também no espaço público e não apenas no recôndito dos lares e das famílias.:

"As mães, as filhas, as irmãs, representantes da nação, solicitam ser constituidas em Assembléia Nacional. Considerando que a ignorância, o esquecimento e o desinteresse dos direitos da mulher são as únicas causas das calamidades públicas e da corrupção dos governos, estas decidiram expor em uma declaração solene os direitos naturais, inalienáveis e sagrados da mulher, com o fim de que essa declaração, constantemente presente na mente de todos os membros do corpo social, thes recorde sempre de seus direitos e de suas obrigações; com o fim de que os atos de poder das mulheres e os de poder dos homens, que podem ser em qualquer momento comparados com a meta de toda instituição política adquiram maior consideração; com o fim de que as reivindicações das cidadãs, baseadas de agora em diante em principios singelos e incontrovertidos, apontem sempre em prol da manutenção da constituição, dos bons costumes, da felicidade de todos os cidadãos". (GOUGES apud DUARTE, 1989)

Considerava a ignorância, o esquecimento e o desprezo aos direitos das mulheres como as causas das desgraças públicas e da corrupção dos governantes, apelando para que seus direitos, em correspondência aos dos homens, pudessem ser respeitados como forma de "manter os bons costumes e alcançar a felicidade para todos". É interessante como defende a igualdade de direitos em relação à educação, justiça, propriedade da terra, sem distinção de sexo, reforçando os valores que fundamentavam os ideais revolucionários da França de 1789. No primeiro artigo da Declaração ressalta a igualdade de direitos entre homens e mulheres no contexto social:

"A mulher nasce livre e permanece igual ao homem em seus direitos. As distinções sociais não podem ser fundadas a não ser no bem comum".

Dialeticamente, contrapunha igualdade de deveres. Argumentava:

"Se as mulheres têm direito de subir ao cadafalso, têm igual direito de ocupar a tribuna". 
O parágrafo final da Declaração é um apelo às mulheres pelo reconhecimento dos seus direitos:

"Mulher, desperta-te; a força da razão se faz escutar em todo o universo; reconhece teus direitos. O poderoso império da natureza não está mais envolto de preconceitos, de fanatismos, de superstição e de mentiras. A bandeira da verdade dissipou todas as nuvens da tolice e da usurpação. O homem escravo multiplicou suas forças e teve necessidade de recorrer às tuas para romper seus os ferros. Tornando-se livre, tornou-se injusto em relação à sua companheira. Oh, mulheres !" (GOUGES apud PIMENTEL; DORA, 1993)

No Brasil, Nisia Floresta (1832) fortemente influenciada por aquelas feministas inglesa e francesa vai dedicar o seu "Direitos das Mulheres e Injustiça dos homens" às mulheres brasileiras e aos acadêmicos de seu tempo.

"Às primeiras porque é delas que trata e por elas escreve. Aliás, perpassa todo o livro uma solidariedade bem feminista, visível no empenho em justificar suas faltas e destacar cada um dos seus méritos. $E$ aos acadêmicos brasileiros porque, afinal de contas, eram eles os representantes legitimos da elite pensante do país, aqueles que poderiam, se quisessem, mudar os rumos dos acontecimentos. Foi desta geração que sairam os futuros abolicionistas, os republicanos e também uns bem poucos - muito poucos - defensores dos direitos da mulher." (DUARTE, 1989)

Nascida em 1809 no Rio Grande do Norte defendeu a abolição da escravatura, o direito à educação, a emancipação das mulheres e a República. Imbuida do espírito e ideais divulgados pelo lluminismo, a autora baseia-se nos conceitos filosóficos fundamentais dentre os quais destaca-se o "primado da razão", isto é, a crença de que o ser humano tem uma vantagem única sobre os demais seres, a capacidade de raciocínio, como a melhor forma de aproximação da verdade. Nisia Floresta, diferentemente de Mary Wollstonecraft, apoia sua argumentação na superioridade das mulheres em relação aos homens: “Não ignoramos que temos razão: essa é a única prerrogativa que a Natureza nos concedeu para elevar-nos acima da esfera dos animais sensitivos; essa mesma razão que nos faz sentir a superioridade que temos sobre eles nos mostraria também a dos homens sobre nós, se pudéssemos descobrir neles o menor grau de senso acima do que temos; mas sem faltar a essa mesma razão não poderiamos reconhecer-nos inferiores a criaturas, cujo bom senso 
de que fazem alarde consiste em entregar-se cegamente às paixões que thes são comuns com os brutos. Se vissemos os homens sempre senhores em ter suas inclinações brutais perfeitamente subordinadas às suas faculdades racionais, poderiamos julgar que a Natureza os destinou para serem nossos senhores, tanto mais que não podemos lisonjear-nos de exercer um império tão completo sobre nós mesmas. Mas como poderiamos conceber uma tal idéia dos homens vendo-os tão ambiciosos de dominar que não podem satisfazer senão com uma autoridade absoluta, solicitar a escravidão a mais vil, prostituindo sua razão às suas paixões grosseiras, deixando cativar seu bom senso pelos prejuízos e sacrificando a um costume pouco judicioso a eqüidade, a verdade e a honra ? Quantas cousas há que essas criaturas soberanamente sábias têm por verdades incontestáveis, sem poderem dar a razão de suas opiniões ? Eis a causa: é porque se deixam levar por aparências; para eles tudo que tem aparência de verdade deve ser tal, porque o ponto de vista sob que descobrem as coisas supre-Ihes a conviç̧ão." (FLORESTA, 1989)

Depois dela várias outras mulheres brasileiras empreenderam lutas e movimentos em prol dos direitos das mulheres, especialmente à educação, ao trabalho e ao voto, esse último só conseguido em 1932 quando Getúlio Vargas promulgou o novo Código Eleitoral. No final da Revolução Constitucionalista D.Carlota Pereira de Queiroz venceu a disputa eleitoral tornando-se assim a primeira deputada federal brasileira dentre os 241 deputados eleitos. (RODRIGUES, 1993)

Quanto aos direitos humanos fundamentais, somente em 1948 a ONU (Organização das Nações Unidas) reviu o documento inicial "Declaração dos Direitos do Homem e do Cidadão" e lançou a "Declaração Universal dos Direitos Humanos", conferindo-Ihe uma nova concepção. Aos direitos iniciais foram incluídos os econômicos, sociais e culturais, referidos às condições de vida compativeis com as necessidades humanas incluindo-se aí o acesso a bens materiais e culturais. Isso também mudou pouco a situação específica das mulheres.

"Nas últimas décadas, fruto da ação de diversos movimentos sociais, surge um conjunto de direitos chamados de 'direitos coletivos' direcionados a proteger as pessoas que constituem minorias de poder: mulheres, crianças e refugiados, entre outros. Tais direitos objetivam proteger a dignidade humana abalada pela discriminação, pelos preconceitos e tudo o que fere a condição humana. Incluem-se neles o direito ao desenvolvimento econômico, direito ao uso racional do meio ambiente, direito à paz, direitos reprodutivos, etc. Essa nova concepção 
de Direitos Humanos considera metas coletivas como a igualdade na diversidade para grupos historicamente discriminados. Para tanto, concebe o sujeito como portador de um sexo, um corpo, uma raça, uma cor, numa certa idade, ou seja, portador de identidade que se forma a partir de certos atributos sociais mesmo que esses tenham origem em atributos biológicos." (CONSELHO, 1998)

Foi nesse contexto que a Conferência de Viena, em 1993, tornou mais clara a noção que os direitos das mulheres são direitos humanos, graças à ação dos movimentos feministas que vêm provocando profundas mudanças sociais a partir de uma nova visão de mundo que questiona a hierarquia entre os sexos e propõe a redefinição dos vínculos entre as pessoas na convivência familiar, comunitária e política.

Várias iniciativas anteriores corroboraram para isso como a Década da Mulher (19751985) iniciada pelo Ano Internacional da Mulher (1975) e pela I Conferência Mundial da Mulher. Em relação aos direitos humanos das mulheres, o fato mais marcante da década foi a "Convenção para a eliminação de todas as formas de discriminação contra a mulher" (1979), promovida pela ONU e ratificada por 101 paises, entre os quais o Brasil. Trata-se do "mais eficaz instrumento internacional que temos hoje de Direitos Humanos para as mulheres." No artigo 12 referente à Saúde e Planejamento Familiar, reza que "os Estados assegurarão: igualdade de acesso aos serviços de assistência médica, inclusive referente ao planejamento familiar e garantia de serviços médicos e de nutrição pré e pós-parto." (CENTRO, 1994)

Seguiram-se vários outros eventos internacionais em que foram discutidos os direitos das mulheres nos mais diversos espaços e modalidades. O auge da luta pela conquista da cidadania foi a IV Conferência Mundial da Mulher realizada em Beijing, na China, em 1995, que reuniu 35 mil mulheres de 185 paises, impressionando o mundo pela grandeza do evento.

Tudo isso mostra que se para Mary Wollstonecraft e Olympe de Gouges a dificuldade era colocar no papel e terem aceitos os direitos das mulheres, isso hoje é fato concreto. Resta faze-los migrar das letras para a vida. Para isso, no dia 8 de dezembro passado, em Nova York, o Womens's Global Leadership Center (Centro para Liderança Global da Mulher) e o UNIFEM (Fundo das Nações Unidas para a Mulher) deram início à Campanha Mundial pelos Direitos Humanos das Mulheres com os lemas 
"Imaginemos um Mundo onde todas as mulheres gozem plenamente de seus direitos humanos" e "Sem os direitos das mulheres não existem direitos humanos".

Os objetivos especificos dessa Campanha são:

- Desenvolver um contexto elevado e coordenado para demandar e cobrar a implementação dos compromissos com relação aos direitos humanos das mulheres;

- Dar maior visibilidade a uma visão afirmativa sobre os direitos humanos das mulheres

- Articular ações e grupos ao nível local num esforço comum a nível mundial

- Reiterar, aumentar e tornar visível a demanda pela responsabilidade do Estado com a implementação dos compromissos assumidos internacionalmente quanto aos direitos humanos das mulheres

Todas as demandas e mensagens deverão ter por base a Plataforma de Ação de Beijing, com o objetivo de:

- Aprofundar o comprometimento com o fim da violência contra a mulher, com ênfase para a violência doméstica e a violência contra as mulheres nos conflitos armados

- Dar maior visibilidade à questão dos direitos econômicos, sociais e culturais

- Promover a ratificação universal da CEDAW (Convenção para Eliminação de todas as formas de Violência contra a Mulher), com a eliminação de todas as reservas à mesma, bem como demanda por um Protocolo Facultativo à CEDAW (forte) e sua subseqüente ratificação. (LIBARDONI, 1998)

Uma das estratégias para a consecução desses objetivos é a promoção do engajamento de todos os países na campanha no sentido de trabalhar pela tradução, leitura e interpretação dos direitos humanos, criando instrumentos especificos para isso. No âmbito da América Latina, o CLADEM (Comitê Latino-Americano de Defesa dos Direitos da Mulher) formulou a "Declaração dos Direitos Humanos desde uma perspectiva de gênero". 
Nessa, as autoras argumentam que "não resta dúvida que a Declaração Universal de 1948 significou e significará sempre um marco na história da construção dos direitos humanos, ao consagrar a universalidade e a indivisibilidade desses direitos. (...) inovou substantivamente a gramática dos Direitos Humanos ao afirmar serem eles universais decorrentes da dignidade inerente a toda e qualquer pessoa e indivisíveis, conjugando assim, imediatamente os direitos civis e políticos com os direitos sociais, econômicos e culturais. A partir da indivisibilidade dos direitos humanos, os valores da liberdade e da igualdade são integrados, compondo uma unidade indivisivel, interdependente e inter-relacionada. Essa concepção foi reiterada em 1993, quando a Declaração de Viena, em seu parágrafo 50, afirmou que todos os Direitos Humanos são universais, indivisiveis, interdependentes e inter-relacionados." (PIOVESAN; PIMENTEL; PANDJIARJIAN; 1998)

Essa chamada gramática dos direitos humanos orienta a proposta do CLADEM (Centro Feminista de Estudos e Assessoria) concernente a uma Declaração de Direitos Humanos sob a perspectiva de gênero, na qual reforça e amplia a concepção de universalidade e de indivisibilidade citadas anteriormente, através de seis categorias: o direito à cidadania, ao desenvolvimento, à paz e a uma vida livre de violência, os direitos sexuais e reprodutivos, o direito ao meio-ambiente, o direito das pessoas e dos povos em razão de sua identidade étnica-racial.

"Em sintese, a proposta objetiva: 1) introduzir a perspectiva de gênero na concepção de direitos humanos, reforçando a universalidade desses direitos; 2) ampliar a noção de indivisibilidade dos direitos humanos, incluindo os direitos de terceira geração (como o direito ao desenvolvimento e ao meio-ambiente) (...) A proposta de uma Declaração Universal de Direitos Humanos a partir de uma perspectiva de gênero busca conferir visibilidade às novas categorias de direitos emergentes nas últimas décadas sob o enfoque de gênero e sob o enfoque histórico de que os direitos humanos não são um dado, mas um construido."(PIOVESAN; PIMENTEL; PANDJIARJIAN; 1998)

\section{O DIREITO À SAÚDE (DAS MULHERES) COMO DIREITO HUMANO}

A Declaração dos Direitos Humanos traz explícito o direito à saúde como forma de alcançar melhor padrão de vida, situando-o portanto como instrumento de acesso à cidadania. 
"Todo homem tem direito a um padrão de vida capaz de assegurar a si e à sua familia saúde e bem-estar, inclusive alimentação, vestuário, habitação, cuidados médicos e os de serviços sociais indispensáveis, e direito à segurança em caso de desemprego, doença, invalidez, viuvez, velhice ou outros casos de perda dos meios de subsistência em circunstâncias fora de seu controle" (CENTRO, 1994)

Com base nisso e nos principios que norteiam tal Declaração, o CFEMEA elegeu as categorias de direitos a serem revistos sob a perspectiva de gênero, conforme explicitado anteriormente. A questão da saúde aparece aí nas diferentes categorias, tangenciando a categoria dos direitos sexuais e reprodutivos onde "destaca-se o direito à autodeterminação no exercício da sexualidade, incluindo o direito à livre orientação sexual, à informação sobre a sexualidade e o direito à educação sexual, lembrando que os direitos reprodutivos fundamentam-se no direito de decidir livre e de maneira informada sobre sua vida reprodutiva. Os direitos sexuais e reprodutivos são concebidos como direitos fundamentais, já que estão estritamente vinculados à liberdade e desenvolvimento da personalidade" (PIOVESAN; PIMENTEL; PANDJIARJIAN; 1998)

Ocorre que no Brasil, desde 1983, a operacionalização das politicas públicas em relação à saúde das mulheres vem sendo feita pelo PAISM - Programa de Atenção Integral à Saúde da Mulher. Nascido num momento de intensa efervescência política e social, e no bojo das transformações estruturais da sociedade brasileira ocorridas a partir do final da década de 70, o PAISM resulta da convergência de diversas forças sociais, entre elas o feminismo como corrente de pensamento e ação social que, a partir da ótica das mulheres, propõe a releitura do biológico da saúde da mulher tomando o social como base para a intervenção. Influenciado também fortemente pelo Movimento de Reforma Sanitária, advogando precocemente o princípio de que a saúde é um direito de cidadania e dever do Estado, além de vários outros pressupostos da Reforma que viriam materializar-se na Lei do Sistema Único de Saúde (SUS), quase uma década depois, o PAISM constitui ainda uma possibilidade pertinente, necessária e atual para a assistência à saúde das mulheres brasileiras. (BRASIL, 1984; BRASIL, 1990)

Segundo D'Oliveira, trata-se de uma organização das práticas de saúde que teve, desde o início, a intenção de trabalhar questões do cotidiano da vida social para além das patologias ou riscos ligados à vida reprodutiva. “Assim, sua noção de 'saúde integral' já pretendia inscrever na atenção à mulher as dimensões psico-sociais integradas à biológica. 
(...) isso ocorreu porque sua formulação se deu em um momento de abertura política e fortalecimento dos movimentos sociais, o que the conferiu um caráter especialmente democrático." (D'OLIVEIRA, 1996)

No documento Assistência Integral à Saúde da Mulher: bases para a ação programática encontra-se claramente definida a intencionalidade do PAISM: redirecionar a política de saúde da mulher, incorporando outras dimensões à assistência nitidamente biologicista e voltada exclusivamente para a função da mulher de reprodutora dos corpos. "O atendimento à mulher pelo sistema de saúde tem se limitado quase que exclusivamente ao período gravídico-puerperal e, mesmo assim, de forma deficiente. Ao lado de exemplos sobejamente conhecidos, como a assistência preventiva e de diagnóstico precoce de doenças ginecológicas malignas, outros aspectos, como a prevenção, detecção e terapêutica de doenças de transmissão sexual, repercussões biopsicossociais da gravidez não desejada, abortamento e acesso a métodos e técnicas de controle da fertilidade, têm sido relegados a plano secundário." (BRASIL, 1984)

Divergindo dos programas anteriores, de cunho eminentemente biologicista, o PAISM representa a primeira experiência concreta de incorporação nas políticas de saúde, da dimensão social, incluídas aí as questões de gênero. "Bem recebido por amplos setores da sociedade, o PAISM passa a constituir o modelo assistencial tido como capaz de atender às necessidades globais da saúde feminina. Incorpora, além da tradicional assistência prénatal, parto e puerpério, tratamento e prevenção das doenças sexualmente transmissíveis, a contracepção e a atenção à esterilidade, a assistência à adolescente e à mulher idosa, a prevenção da gravidez indesejada, a educação em todas as ações dirigidas à mulher (...)e às patologias clínicas mais comuns." (D'OLIVEIRA, 1996)

Em nome disso, o movimento de mulheres mantém a defesa dos seus principios e pressupostos como bandeira de luta, insurgindo-se contra a maneira como tem sido implantado na maior parte do país. Segundo GURGEL (1997) "passado mais de uma década do lançamento do PAISM, podemos avaliar que o conjunto das suas bases foi prejudicado na sua aplicabilidade. O princípio da integralidade foi reduzido aos casos de processos associados à procriação e assim mesmo com inúmeras debilidades na maior parte do país".

Para SORRENTINO (1994), “o movimento pela reforma sanitária e o movimento de mulheres vêm caminhando juntos em sua luta pela saúde, realizando inúmeras ações em comum (...) Entretanto, isso nunca significou, na verdade um entrosamento maior (...) A 
importância do PAISM para o SUS precisa ser rediscutida. O PAISM é visto, muitas vezes, como um novo direito a ser reconhecido, uma espécie de prática alternativa a ser implantada, sem status de ciência ou de prioridade dentro da política de saúde. Refiro-me aqui à importância da saúde da mulher para o conjunto do sistema de saúde e o impacto que medidas de atenção à saúde da mulher trariam para a estrutura desse sistema."

Se existe o reconhecimento de que entre o SUS e o PAISM ainda há difícil convivência, o que se dirá então a respeito das dificuldades de implantação de ambos no contexto atual da estruturação dos serviços de saúde gestados na política neoliberal que caracteriza os governos brasileiros dos anos 90 e que têm praticamente inviabilizado o próprio SUS ? Tais dificuldades são identificadas por SORRENTINO (1994) quando lembra que "o SUS é parte maior de um sistema de saúde e de organização social. Ele representa um avanço mas não é independente da realidade mais geral. O projeto neoliberal transformou a municipalização em acelerado processo de privatização e desmanche do Estado, na medida em que desobriga o nível central de muitas de suas antigas funções. A crise e a ausência de verbas e de prioridade para o setor social levam a problemas mais graves, ou seja, não podemos nos esquecer que é no contexto do SUS que se dá a luta pelo PAISM".

A implantação do modelo econômico neoliberal, principalmente através da proposição de um Estado mínimo, normativo e administrador, que não interfira no funcionamento do mercado e cujas ações se voltem para o aprofundamento das desigualdades vem contribuindo para acirrar as diferenças entre os grupos sociais em termos de acesso aos bens de consumo, entre eles, os de saúde. Nesse contexto, como implantar políticas e práticas adversas ao sistema, como o SUS e o PAISM ?

Segundo BARROS (1996) "é desnecessário hoje ressaltar a multideterminação da saúde, porém é indispensável chamar a atenção para que a decorrência dessa assertiva deve ser a incorporação de todas as áreas de ação do Estado no objetivo de construir a saúde. "Mais que hospitais, o que precisa ser assegurado aos cidadãos é a qualidade de vida. Essa é mais uma das razões pelas quais a existência de um sistema público estatal de atenção à saúde é importante numa sociedade como a brasileira. Ele deve ser também um espaço catalisador de ações multisetoriais, promotor da articulação de políticas públicas necessárias para assegurar a saúde e interromper os ciclos de transmissão das doenças. (...) Numa sociedade que tem os niveis de exclusão da nossa, em que pelo menos $20 \%$ da população sobrevive em condições extremamente precárias, em decorrência de um processo histórico de desenvolvimento que produziu uma das mais desiguais distribuições de renda 
do mundo, a garantia do direito à saúde não pode prescindir de uma estratégia integrada de ação estatal."

Há que se lembrar que no caso das mulheres o processo de exclusão causado pelo projeto neoliberal tem imputado à mulher condições extremamente precárias de vida e trabalho com sérias implicações para o seu processo saúde-doença. A ideologia neoliberal aponta que o caminho do progresso está marcado pelo crescimento produtivo que se expressa pelo aumento das taxas de lucro e competitividade nos grandes negócios, obtidos às custas de um marcado processo de concentração e monopolização dos meios de produção, do controle oligopólico do mercado, submetendo os trabalhadores a condições de remuneração decrescentes sem falar na falta de controle e melhoria de condições de trabalho subjacente ao processo de barateamento dos custos de produção. As mulheres têm sofrido mais que os homens esses processos pela subvalorização do seu trabalho, tanto no âmbito do mercado produtivo quanto nas tarefas constituintes do trabalho doméstico, historicamente femininas. Na constituição das sociedades pós-modernas, vários processos destrutivos da vida das mulheres têm sido detectados:

1. aumento na proporção de mulheres chefes de familia sem os suportes jurídicos e salariais vigentes para os homens;

2. agudização do processo de subvalorização do trabalho feminino (expansão do trabalho feminino de baixa qualificação; feminização e conseqüente desvalorização social de algumas profissões; falta de condições seguras de trabalho para as mulheres que, mais que os homens se submetem a condições insalubres e deletérias ao seu processo saúdedoença como forma de complementação orçamentária familiar em tempos de crise; remuneração mais baixa que a dos homens pelas mesmas atividades; etc)

3. agudização do peso da tripla carga de trabalho para possibilitar as condições de sobrevivência familiar (trabalho produtivo remunerado, trabalho doméstico de cuidado das crianças e dos trabalhadores, trabalho relativo à geração de novos sujeitos sociais sem a eqüidade da participação masculina). A essas somam-se as atividades político-participativas dado o crescente número de mulheres que se inserem nos movimentos sociais e a importância desses movimentos no processo de transformação social.

4. agudização da falta de bens de consumo e serviços, tanto gerais como específicos para dar suporte às atividades femininas. (BREILH, 1995; SUÁREZ, 1995) 
Pouco disso, no entanto, tem sido levado em conta quando se pensa nos processos assistenciais à saúde das mulheres, exceto conforme se falou antes na formulação do PAISM, a despeito da precariedade da sua implantação que como se falou, deveria ser nos mesmos âmbitos e marcos do SUS.

Para BARROS (1996), o sistema de saúde brasileiro deveria ter as algumas características básicas para que a população brasileira pudesse ter garantido seus direitos. A seguir, enumero tais características, particularizando a situação das mulheres (entre colchetes)

- Deve ser acessível a todo cidadão, independente de sua capacidade financeira ou de sua forma (ou possibilidade) de inserção no mercado de trabalho.

[Se lembrarmos que as condições de inserção das mulheres no mercado de trabalho são extremamente diferenciadas (para pior) que para os homens, tal principio deveria levar em conta essa diferenciação e estabelecer mecanismos sociais que assegurem às mulheres condições objetivas de acesso ao sistema de saúde]

- Deve ser capaz de responder às exigências postas pela transformação do quadro demográfico e dos perfis epidemiológicos, garantindo a adequação das ações às demandas postas pelos diferentes quadros sanitários, nas diversas regiões do pais.

[No caso específico das mulheres, tais mudanças nos perfis epidemiológicos referem-se ao incremento dos problemas de saúde como as doenças crônicodegenerativas e decorrentes das condições de trabalho, doméstico ou extradoméstico, às patologias especificas femininas, referentes à reprodução biológica. Nesse sentido, adquire importância a noção de integralidade trazida pelo PAISM exposta anteriormente para dar conta das demandas de saúde das mulheres, especialmente no que se refere aos direitos reprodutivos e de saúde e trabalho.]

- Deve ter como objetivo a construção e a preservação da saúde e não apenas a cura da doença.

[No caso das mulheres, a saúde reprodutiva e saúde em geral pode ser um instrumento para a consecução do seu direito à cidadania, a partir da 
compreensão de que a saúde é determinada pela qualidade de vida subordinada à condição de gênero. Assim, a superação das desigualdades é condição sine qua non para a melhoria da situação de saúde das mulheres]

- Deve operar de modo articulado, sujeito aos mesmos princípios e diretrizes, viabilizando a integralidade dos cuidados com saúde e oferecendo serviços de boa qualidade.

[A noção de integralidade do PAISM passa tanto pela intenção de integrar as várias modalidades da assistência, nos diversos níveis, como também pela atenção integral que se refere à assistência à mulher nas diversas fases da sua vida (adolescente, menina, adulta, menopáusica). Acresce-se a isso a idéia de integração bio-psico-social, fortemente inspirada na idéia de sensibilização através da ação educativa. (SCHRAIBER ;1997)]

- Deve, para assegurar tudo isso, contar com um processo decisório participativo e submeter-se ao controle dos sujeitos sociais.

[Desde a sua concepção até a implantação e críticas atuais, o PAISM tem sido monitorado pelos movimentos feministas e de mulheres como alternativa pela qual tem valido a pena lutar, dado ter sido concebido como demanda desses movimentos para a superação da problemática de saúde das mulheres, cada vez mais adversa à sua dignidade e exercício da cidadania]

Para finalizar, BARROS (1996) explicita que o sistema de saúde brasileiro, para dar conta da problemática de saúde vigente deve ser, em resumo, respaldado nos princípios de “acesso universal, integralidade da atenção, ênfase em ações de promoção e proteção da saúde, descentralização e participação social. Exatamente o que a legislação brasileira hoje em vigor - e ainda não inteiramente implementada - propõe para o SUS". No caso específico das mulheres, eu acrescentaria: exatamente o que o PAISM preconiza para a atenção à saúde das mulheres baseado na concepção dos seus direitos à luz da perspectiva de gênero.

\section{FINALIZANDO ...}

Pensar nos direitos das mulheres (e neles, o direito à saúde) implica redefinir o que se entende por mulher/vida de mulher, direito e saúde. Acredito ainda que isso deva ser feito à luz da perspectiva de gênero para que se possa compreender as necessidades das mulheres 
e como elas podem servir de mote para a formulação e implementação de políticas públicas que visem a superação da condição de subalternidade feminina. Visto dessa forma, o PAISM constitui um excelente instrumento para a consecução dessa finalidade, se mantida a sua vocação inicial de recolocar a questão da saúde das mulheres determinada antes pelo social que exclusivamente pelo biológico.

Para finalizar, pontuo a propriedade e pertinência das reflexões para a constituição das politicas locais aspiradas desde uma perspectiva emancipatória para as mulheres e, por que não, para os homens, à sua semelhança, na defesa de que é na compartilha de conhecimentos e experiências que reside a real oportunidade de nos tornarmos (coletivamente) cidadãs e cidadãos de primeira categoria, na luta por um mundo justo e digno.

\section{REFERÊNCIAS BIBLIOGRÁFICAS}

BADINTER, E. Um amor conquistado: o mito do amor materno. Trad. De Waltensir Dutra. Rio de Janeiro, Nova Fronteira, 1986. 309p.

BARROS, E. Política de saúde no Brasil: a universalidade tardia como possibilidade de construção do novo. Ciênc. \& Saúde Col., 1(1):5-17, 1996.

BREILH, J. Gênero, poder y salud: aportes críticos a la construcción (intergenérica) de una sociedad sin subordinaciones. Quito, Ibarra Ediciones, CEAS-UTN, 1994. (Série Mujer n. 3)

CENTRO DE FEMINISTA DE ESTUDOS E ASSESSORIA (CFEMEA) Guia dos direitos da mulher. Brasilia, 1994.

COMBES, D. \& HAICAULT, M. Relações sociais de sexo e de classes. In: KARTCHEVSKY, A. P.B.et al O sexo do trabalho. Rio de Janeiro, Paz e Terra, 1986. p.23-43.

CONSELHO ESTADUAL DA CONDIÇÃO FEMININA DE SÃO PAULO. Os direitos das mulheres são direitos humanos. São Paulo, CECF, 1998.

D'OLIVEIRA, A.F.P.L. Gênero e violência nas práticas de saúde: contribuição ao estudo da atenção à saúde da mulher. São Paulo, 1996. [Dissertação de Mestrado: Faculdade de Medicina da Universidade de São Paulo.] 
DEVELOPMENT ALTERNATIVES WITH WOMEN FOR A NEW AGE (DAWN). Development, crisis and alternatives visions; Third World women perspectives. Delhi, DAWN, 1985.

DUARTE, C. Pósfacio: nos primórdios do feminismo brasileiro. In: FLORESTA, N.B. Direitos das mulheres e injustiça dos homens. São Paulo, Cortez, 1989. p. 99-134.

FLORESTA, N.B. Direitos das mulheres e injustiça dos homens. São Paulo, Cortez, 1989.

FONSECA, R.M.G.S. da Atenção: mulheres trabalhando - na vida, na saúde, na enfermagem. In: FONSECA, R.M.G.S. da, org. Mulher e cidadania na nova ordem social. São Paulo, NEMGE, $1996 a$.

FONSECA, R.M.G.S. da Mulheres e enfermagem: uma construção generificada do saber. São Paulo. [Tese de Livre Docência - Escola de Enfermagem da Universidade de São Paulo. 1996b]

FOX-GENOVESE, E. Para além da irmandade. Estudos Feministas, 3:31-56, 1992. Rio de Janeiro.

GURGEL, T. PAISM no olhar de gênero. [Apresentado no Seminário Mulher, saúde e cidadania promovido pela Escola de Enfermagem da Universidade Regional do Rio Grande do Norte, Mossoró, maio de 1997.]

LÁZARO, C.L.A. Nosso credo. Mandrágora, 1(1):83, 1994

LIBARDONI, M. Campanha mundial pelos direitos humanos das mulheres de 1998. Fêmea, $6\left(n^{\circ}\right.$ esp.):2-4, 1998.

MATOS, M.I.S. Experiências femininas: o público, o privado e o intimo. [Apresentado ao Encontro Enfoques Feministas e Tradições Disciplinares na Ciência e na Academia: Desafios e Perspectivas. Universidade Federal Fluminense, Rio de Janeiro, 16 a 19 de agosto de 1994.]

MENEZES, G.M.S. Trabalho noturno e saúde: um estudo com profissionais de enfermagem de um hospital público em Salvador, Bahia. Salvador, 1996. [Dissertação de Mestrado - Instituto de Saúde Coletiva da Universidade Federal da Bahia]

MINAYO, M.C. de S. O desafio do conhecimento: pesquisa qualitativa em saúde. São Paulo, HUCITECIABRASCO, 1992. 
MOLINEAUX, M. Movilización sin emancipación ? Los intereses de la mujer, Estado y revolución en Nicarágua. Desarrollo Soc., 18:178-95, 1984

MOSER, C. Planificación de género y desarrollo: teoria, práctica y capacitación. Lima, Flora Tristán Ed., 1995.

OLIVI, M.L. A mãe sob suspeita: a compreensão da assistência à saúde do escolar através do estudo dialético das concepções dos envolvidos. São Paulo, 1996. [Tese de Doutorado - Escola de Enfermagem da Universidade de São Paulo]

PIMENTEL, S. \& DORA, D.D. As mulheres e a construção dos direitos humanos. São Paulo, CLADEM, 1993.

PIOVESAN, F.; PIMENTEL, S. \& PANDJIARJIAN, V. Declaração de Direitos Humanos a partir de uma perspectiva de gênero: uma contribuição ao $50^{\circ}$ aniversário da Declaração Universal de Direitos Humanos. Fêmea, 6 ( $n^{\circ}$ esp.):5-6, 1998.

RODRIGUES, J.B.C. A mulher brasileira: direitos políticos e civis. Brasília, Centro Gráfico do Senado Federal, 1993.

SCHRAIBER, L.B. Integralidade: possibilidade ou utopia na construção dos modelos assistenciais no SUS./ Apresentado na Oficina de Trabalho Gênero e Políticas públicas: atualizando a agenda promovida pela Grupo de Trabalho Gênero e Saúde da Associação Brasileira de Pós-graduação em Saúde Coletiva (ABRASCO). V Congresso Brasileiro de Saúde Coletiva e V Congresso Paulista de Saúde Pública, Águas de Lindóia (SP), 26 a 29 de agosto de 1997. anotações pessoais.

SORRENTINO, S. O SUS e a saúde da mulher. J. Rede, 2(7):1, 1994.

SUÁREZ, M. Sexo/gênero na epidemiologia. [Apresentado à Oficina de Trabalho "Gênero e Saúde: estado atual da produção do conhecimento epidemiológico, lacunas e desafios". $3^{\circ}$ Congresso Brasileiro $2^{\circ}$ Congresso Ibero-Americano $1^{\circ}$ Congresso Latino-Americano de Epidemiologia, Salvador, 1995.]

WALLERSTEIN, N. Empowerment education applied to youth. In: MATTIELLA, A.C. The multicultural challenge in health education. Santa Cruz, CALIFÓRNIA, ETR Associates Publishers, 1994. p.153-76 


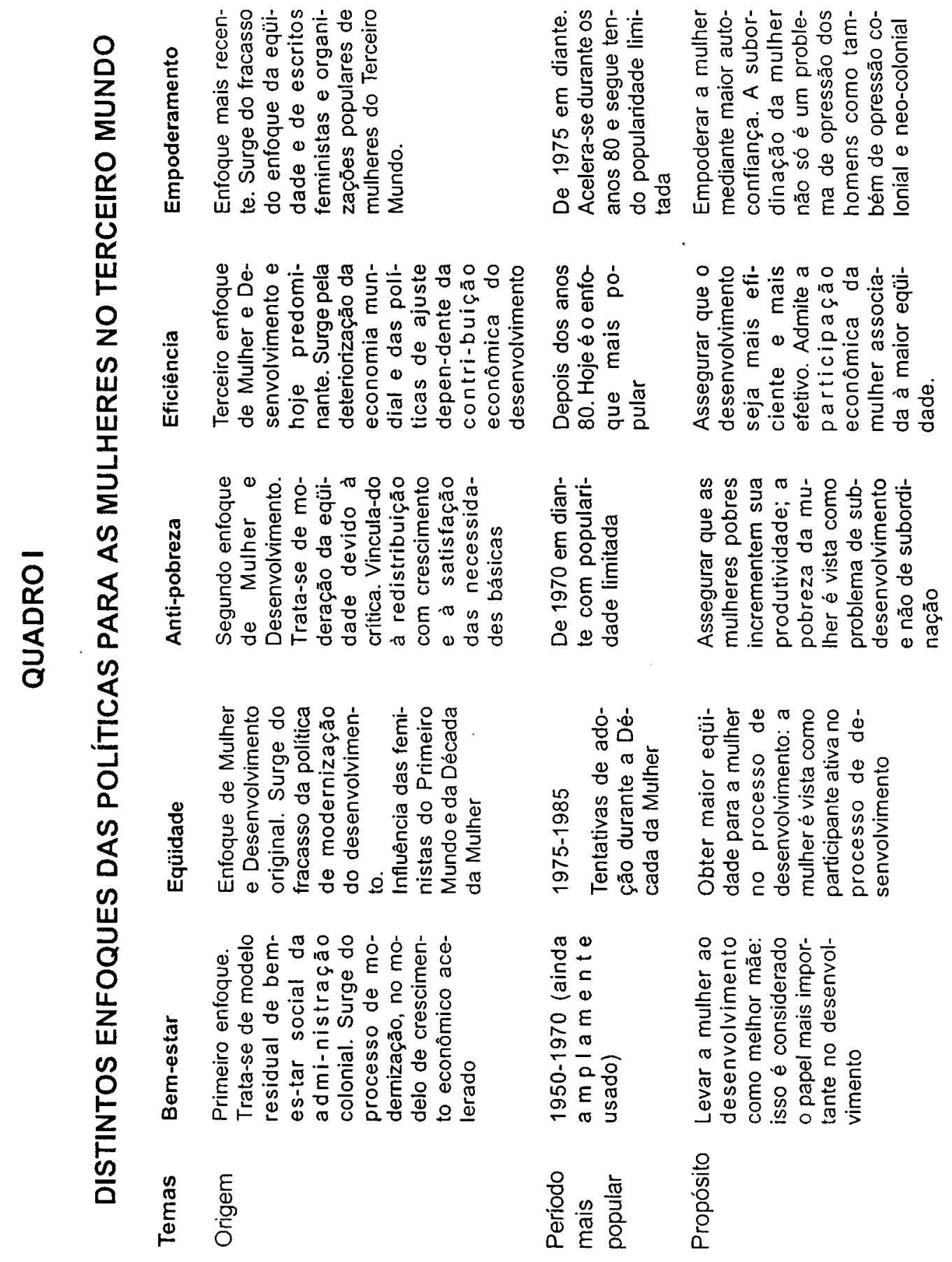




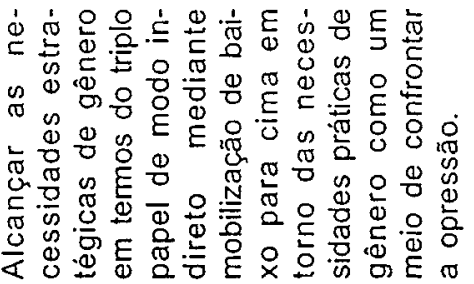

运

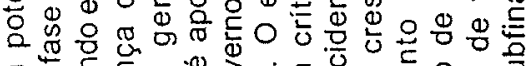

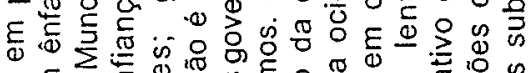

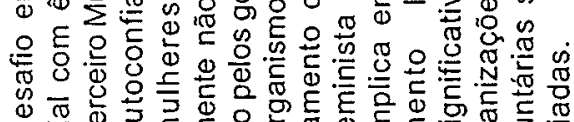

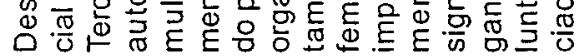

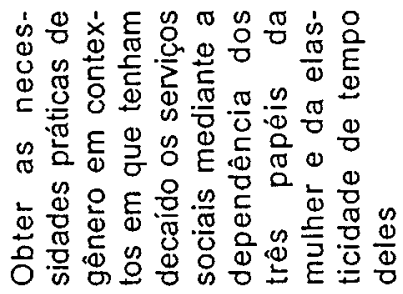

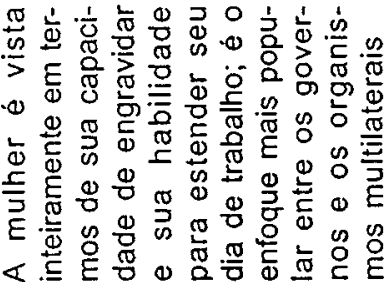
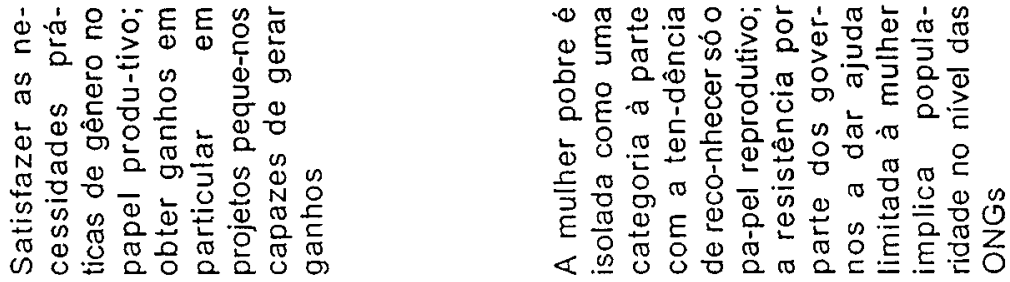

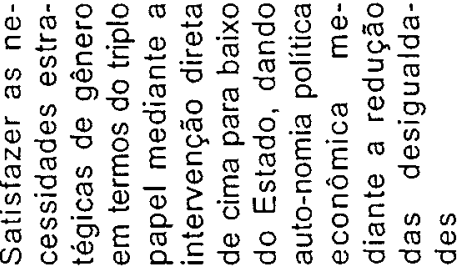

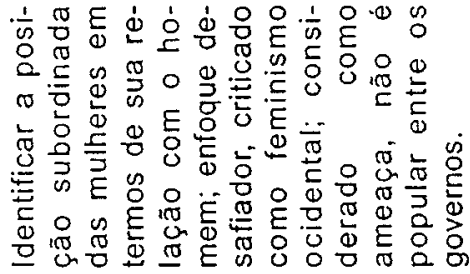

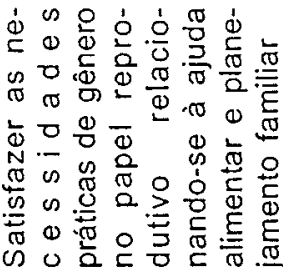

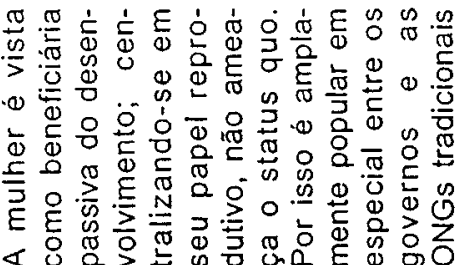

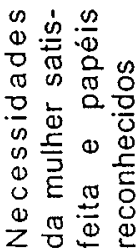

足

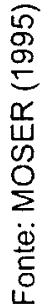




\section{WOMEN, RIGHTS AND HEALTH}

SUMMARY: That article is built from three basic elements: women, rights and health, articulated to each other starting from: 1) considerations concerning the objective conditions of the women's constitution as social subjects in contemporary society; 2) women's rights as human rights and 3) women's rights to health in the context of PAISM (Program of Integral Attention to the Woman's Health), as part of SUS (Unified System of Health).

UNITERMOS: gender and health, women's rights, women's right to health, PAISM/ SUS

Recebido: 24/2/99

Aprovado: $16 / 8 / 99$ 